\title{
49. A Method Delineating a Curve Representing the Manner of Variation of Chemical Composition in a Zoned Plagioclase.
}

\author{
By Fujio Homma. \\ Geological and Mineralogical Institute, Kyoto Imperial University. \\ (Comm. by T. OGaWA, M.I.A., May 12, 1936.)
}

In 1932, Prof. S. Kōzu and S. Watanabe reported a paper on the zonal structure of plagioclase phenocrysts in pumice ejected from Komagataké in 1929 with illustrations representing some composition-variation curves of plagioclase. Discussing the origin of complicated zonal structures found in the crystals studied, they suggested that the investigation on the zonal structure would be very important to elucidate the history of the crystal growth. The present writer have also measured plagioclase crystals found in various igneous rocks.

During the practice of the measurement he devised a method constructing an exact composition-variation curve of zonal crystal. It can be carried out by a twofold method of drawing an extinction-variation curve and its transformation to the composition-variation curve. A study on a nearly idiomorphic crystal in quartz diorite collected from Tenmokuzan, $4 \mathrm{~km}$ 's north of Hazikano railway station, Yamanashi Prefecture was exemplified as follows.

I. Preparatory Work.

A thin section (No. 340746) was inspected under an ordinary petrographical microscope to know the general petrographical features of the rock and to find a crystal fit for measurement. Then; in order to take photograph, the crystal was rotated to the position where the zonal structure is observed most distinctly between the crossed nicols. On the photograph made (fig. 1), a line, XY, was drawn from the center to the periphery of the crystal, indicating the posi-

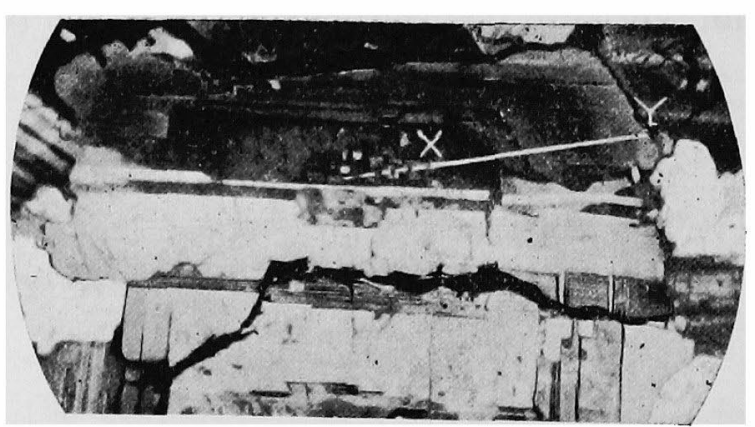

Fig. 1. tion along which the variation curve was made.

II. The Method Constructing an Extinction-Variation Curve.

a. The thin section being mounted on the universal microscope, the crystal was laid at the position where it had been photographed. The length corresponding to XY was taken as the abscissa, on which the numbers of division corresponding to the width of each zone were measured by the aid of the ocular micrometer (fig. 2).

b. The three axes of the universal stage $(\mathrm{N}, \mathrm{H} \& \mathrm{~K}$ axes after von M. Reinhard) were then rotated to find the position where the zonal structure could be observed more clearly than it was done under 


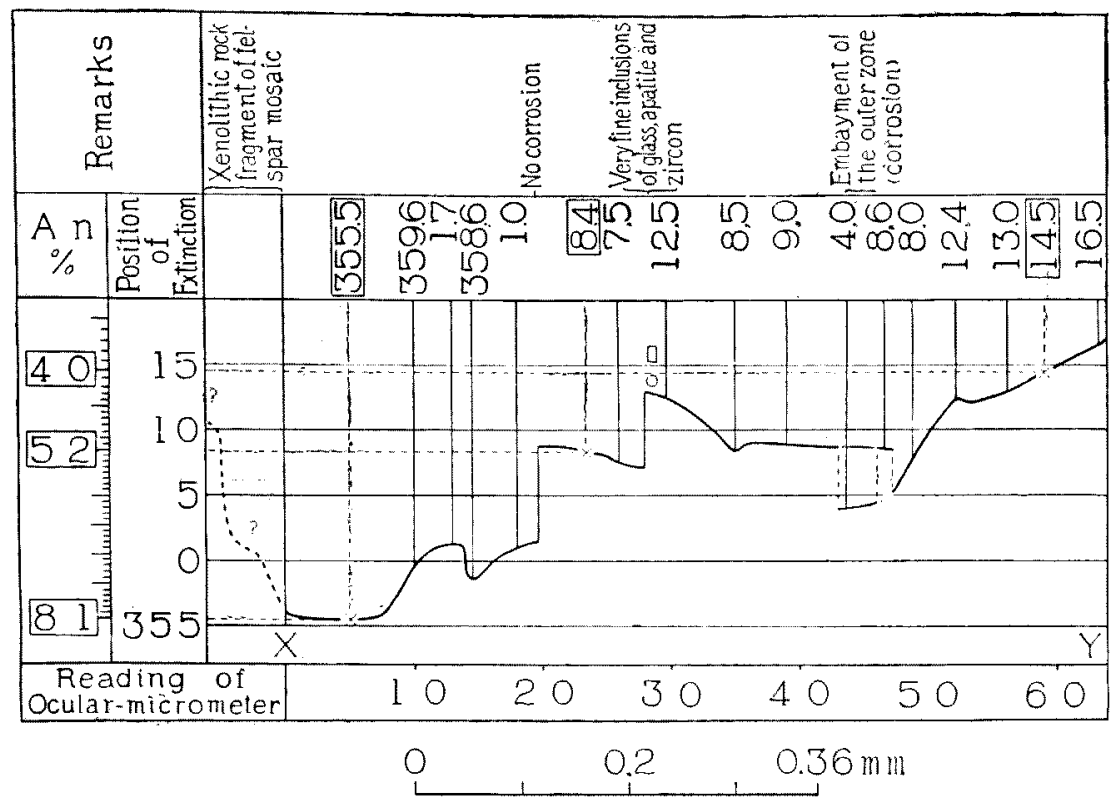

Fig. 2.

the ordinary microscope. After fixing the position on the universal stage, the $\mathrm{M}$ axis, or the microscope axis, was rotated in order to scale on the ordinate with sufficient degrees corresponding to the extinctionpositions of all zones (fig. 2).

c. Refering to the ordinate, many points, which correspond to the degrees representing the extinction-positions of the measured points, were taken on the lines normal to the abscissa drawn from there. These points were then connected accurately with the aid through the direct observation of the extinction phenomena under the microscope.

d. Lastly, by the rotation of three axes, it was examined (1) whether or not an inner zone passed continuously to the outer, (2) where the trace of resorption was, (3) how the various kinds of inclusion were distributed in zones and (4) whether or not further minor zonal structures were observable in an individual zone.

III. Transformation of the Extinction-Variation Curve to the Composition-Variation Curve.

a. Three zones with considerable width were measured under the universal microscope to determine the anorthite percentage (An \%) (fig. 2). For the estimation of An \%, the same curve, (010) of Berek, was only used in order to get the exact relative values.

b. Basing on the above measurements, another ordinate, the column for An \% in fig. 2, was constructed by interpolation.

c. Since the interval for each one percent of anorthite was not equal in fig. 2, fig. 3 was drawn in order to hold the equal interval for each $1 \%$ An.

IV. Classificatory Treatment of the Zonal Structure.

In favor of the genetical explanation of the zonal structure, the curve consisting of eight parts, named as "zone," was divided into the calcic central zones (Group I) and the outer sodic ones (Group II) by a boundary line of chemical discontinuity, on which a difference was 


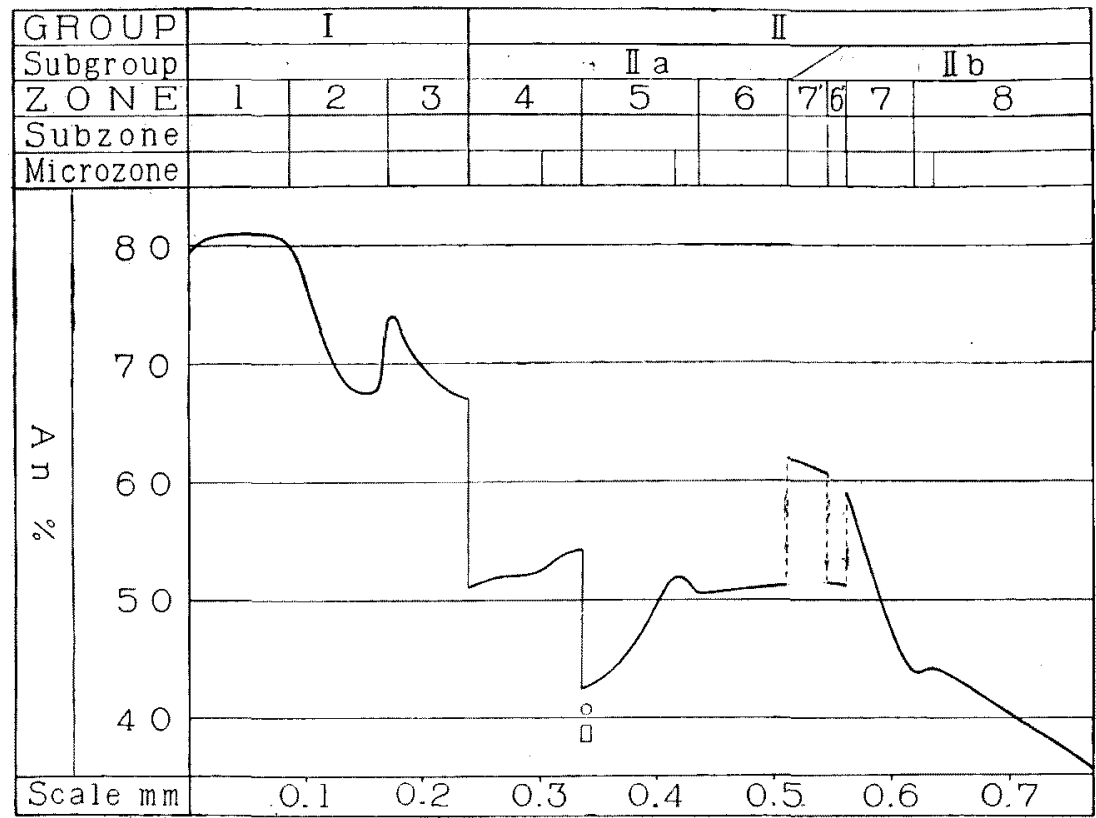

Fig. 3.

measured by nearly $16 \%$ of anorthite. By a zone of corrosion the outer group was further divided into two subgroups and some of individual zone were classified to minor zones, named as "microzones."

V. Some Genetical Explanations.

The calcic centre such as $81 \%$ of An shows that the composition of the original magma was basic, or basltic, because the centre could not be considered from every respect to be a xenocryst. A sudden change in composition on the dividing line between the central and outer groups would be explained by an intrusion of an upper acidic part of the magma, including the measured crystal, to anywhere nearly free from the effect of the mother liquid.

As the nucleus of this kind of crystal, there was usually a xenolithic rock fragment composing of fine felspar mosaic with a few augite grains. It gives an appearance resembling to diabase, around which the growth of the crystal was started: the fact also suggests that the original magma was basic in composition.

The helps were given from the fund for the scientific investigation in the Imperial Academy, for the collection of the rock specimens, studied, and the Foundation for the Promotion of the Scientific and Industrial Research of Japan, for the laboratory works. To those the writer's acknowledgements are given. 